\title{
Higher physiotherapy frequency is associated with shorter length of stay and greater functional recovery in hospitalized frail older adults: a retrospective observational study
}

Peter Hartley ${ }^{1}$, Jennifer Adamson ${ }^{1}$, Carol Cunningham ${ }^{1}$, Georgina Embleton ${ }^{1}$, Roman Romero-Ortuno $0^{2,3}$

${ }^{1}$ Department of Physiotherapy, Addenbrooke’s Hospital, Cambridge, United Kingdom

${ }^{2}$ Department of Medicine for the Elderly, Addenbrooke’s Hospital, Cambridge, United Kingdom

${ }^{3}$ Clinical Gerontology Unit, Department of Public Health and Primary Care, University of Cambridge, United Kingdom

Correspondence:

Peter Hartley, Department of Physiotherapy, Box 185, Addenbrooke's Hospital, Cambridge University Hospitals NHS Foundation Trust, Hills Road, Cambridge, CB2 0QQ, United Kingdom. Email: peter.hartley@addenbrookes.nhs.uk; Telephone: +44 1223274438

Physiotherapy frequency and hospital outcomes 


\begin{abstract}
Extra physiotherapy has been associated with better outcomes in hospitalized patients, but this remains an under-researched area in geriatric medicine wards. We retrospectively studied the association between average physiotherapy frequency and outcomes in hospitalized geriatric patients. High frequency physiotherapy (HFP) was defined as $\geq 0.5$ contacts/day. Of 358 eligible patients, 131 (36.6\%) received low, and 227 (63.4\%) HFP. Functional improvement (discharge versus admission) in the modified Rankin scale was greater in the HFP group (1.1 versus 0.7 points, $\mathrm{P}<0.001)$. The mean length of stay (LOS) of the HFP group was 6 days shorter ( 7 versus 13 days, $\mathrm{P}<0.001$ ). After adjusting for age, gender, comorbidity (Charlson index), frailty (Clinical Frailty Scale), dementia and acute illness severity, HFP was an independent predictor of functional improvement, shorter LOS and likelihood of being discharged without a formal care package. Prospective research is needed to examine the effect of physiotherapy frequency and intensity in geriatric wards.
\end{abstract}

\title{
Keywords
}

Frail Elderly

Physiotherapy

Observational study

Outcomes assessment

England 


\section{Introduction}

Frail older people have increased vulnerability to poor resolution of homeostasis following a stressor event (1), such as an illness or fall necessitating an admission to hospital. In frail older adults, hospitalization is associated with longer length of stay (LOS) (2, 3), and sometimes it can lead to physical deconditioning and loss of functional ability (4).

Pressures on hospital bed occupancy in the English National Health Service (NHS), in part driven by an increasing frail older population $(5,6)$, have focused attention on enhanced service delivery models and potential methods by which physiotherapists might contribute to effective cost savings, while retaining a patient centered approach.

A previous systematic review showed that extra physical therapy can decrease LOS and significantly improve mobility within specialties such as stroke, orthopedics and cardiothoracic surgery (7). Previous studies have also reported on the benefit of rehabilitation for frail patients in the acute care setting for improving function and gait speed $(8,9)$. However, the association between physiotherapy frequency and hospital outcomes in acute hospital geriatric medicine wards, where the prevalence of frailty is very high (10), remains underresearched.

The aim of our study was to retrospectively investigate whether physiotherapy frequency in patients admitted to our Department of Medicine for the Elderly (DME) wards was associated with LOS and functional outcomes, after adjusting for frailty and other possible confounders. 


\section{Methods}

Setting and participants

This was a retrospective observational study in a large tertiary university NHS hospital in the United Kingdom. We analyzed all first admission episodes of non-institutionalized people within the county boundaries admitted to DME wards between $1^{\text {st }}$ December 2014 and $30^{\text {th }}$ May 2015 who came from their own home and returned to it.

\section{Measures}

The following measures were extracted from the hospital's electronic information systems:

- Age (years) and gender.

- Clinical Frailty Scale (CFS) (11). A local Commissioning for Quality and Innovation (CQUIN) scheme (http://www.institute.nhs.uk/commissioning/pct_portal/cquin.html) implemented in our hospital in 2013 mandated that all patients aged 75 years or over admitted to the Trust via the emergency pathway be screened for frailty using the CFS within 72 hours of admission. Our centre uses the 9-point CFS (http://geriatricresearch.medicine.dal.ca/clinical_frailty_scale.htm).

- Charlson comorbidity index (CCI) (12) (without age adjustment).

- Whether there was a formal diagnosis of dementia prior to admission (yes/no).

- Emergency Department Modified Early Warning Score (ED-MEWS, highest recorded in the ED). MEWS scores are considered as a measure of acute illness severity (13).

- LOS, days.

- Average physiotherapy frequency was calculated by dividing the total number of physiotherapy contacts during the admission by the LOS in days. High frequency physiotherapy was defined as $\geq 0.5$ contacts/day.

- The modified Rankin Scale (mRS) was used as a measure of function $(14,15)$. Higher 
scores on the mRS denote higher disability ( $0=$ no symptoms at all; $5=$ severe disability). Scores were retrospectively collected for baseline (preadmission), admission, and discharge. Functional change was defined as the difference between discharge and admission mRS.

- Existence of a formal care package on discharge (yes or no).

\section{Analyses}

Anonymized data was analyzed with IBM SPSS Statistics (version 22) software. Descriptive statistics were given as count (with percentage) or mean (with standard deviation (SD)). To statistically test for differences between the characteristics and outcomes of patients who received high and low frequency of physiotherapy, the non-parametric Mann-Whitney U test was used to compare means for continuous variables, and the Chi-squared test was used for dichotomous variables. Multivariate linear regression models were used to assess the independent effect of high physiotherapy frequency on functional gain (i.e. $\mathrm{mRS}$ on discharge minus mRS on admission) and LOS, while controlling for potential confounders. A multivariate binary logistic regression model was used to assess the independent effect of high frequency physiotherapy on whether patients had a formal care package on discharge. The level of statistical significance was set at $\mathrm{P}<0.05$, and $\mathrm{P}<0.1$ was considered as statistical trend.

\section{Ethics Approval}

This Service Evaluation Audit was registered with our centre’s Safety and Quality Support Department (Project Register Number 4794). Formal confirmation was received that approval from the Ethics Committee was not required. 


\section{Results}

There were 663 first hospital episodes over the period. Of those, 72 died as inpatient and were excluded. Of the remaining 591, 361 were admitted and discharged from their own home. Of those, 3 had missing physiotherapy frequency data. Of the remaining 358, 131 (36.6\%) had low, and 227 (63.4\%) high physiotherapy frequency.

Patient characteristics and outcomes are reported in Table 1. A significant difference between low and high physiotherapy frequency groups was the level of function on admission, with the low frequency group seeming to have better function. There was a suggestion that the low frequency group included more patients with history of dementia $(\mathrm{P}=0.065)$. Functional improvement was more marked in the high frequency group (1.1 versus 0.7 points, $\mathrm{P}<0.001)$, but there was no significant difference between discharge mRS scores. As regards outcomes, the mean LOS of the high frequency group was 6 days shorter ( 7 versus 13 days, $\mathrm{P}<0.001$ ), and there was a suggestion that more people in the high frequency group were discharged without a formal care package $(\mathrm{P}=0.085)$. There was no significant difference in readmission rate at 30 days.

The results of the multivariate analyses are shown in Table 2. After adjusting for age, gender, CFS, CCI, history of dementia and ED-MEWS, high frequency physiotherapy was an independent predictor of functional improvement $(\mathrm{P}=0.003)$, shorter $\operatorname{LOS}(\mathrm{P}<0.001)$ and being discharged without a formal care package $(\mathrm{P}=0.015)$. The strongest multivariate effect of high frequency physiotherapy was seen in LOS, where seeing the physiotherapist at least every second day was associated with a 5.8-day reduction in LOS, after full adjustment. 


\section{Discussion}

This study retrospectively examined the association between average physiotherapy frequency and functional trajectories and outcomes in acutely hospitalized older adults. In our busy NHS geriatric wards, the majority of eligible patients (63.4\%) saw the physiotherapist at least every second day. High average frequency of physiotherapy was associated with a markedly shorter LOS, greater functional improvement from admission to discharge and higher odds of not needing a formal care package on discharge. Causality cannot be inferred from this retrospective cross-sectional study, but results would suggest that frail older people admitted to geriatric wards might benefit from seeing a physiotherapist at least every second day. The associations emerging from our retrospective study are by no means causal, and would necessitate further exploration in appropriately designed prospective studies.

There appeared to be no difference in disability between the two groups at pre-admission or discharge, as measured by the mRS, but the high frequency physiotherapy group seemed to experience a larger loss of function associated with admission into hospital. It appears logical that those who have lost the most function will have the most to benefit from physiotherapy input, as they would have the most function to regain. A surprising finding was that it was greater disability at admission rather than less disability at baseline that seemed to be responsible for the greater difference in the functional change for the high frequency group. This being a retrospective study, we cannot claim cause and effect between greater average frequency of physiotherapy and faster recovery rates. However, it would be difficult to otherwise explain why people with greater disability on admission had a shorter LOS and were discharged with the same level of disability as those with low frequency physiotherapy input. In any case, we emphasize that confirmation of this possible effect would necessitate further exploration in appropriately designed prospective studies. Another important 
limitation of our study was the lack of description of the dose and the distribution of the physiotherapy sessions throughout the patients’ LOS.

There was a trend in Table 1 for more patients with dementia receiving low frequency physiotherapy, and it is possible that cognitive and other unmeasured patient characteristics might have been responsible for the cross-sectional differences seen between the high and low frequency groups. Indeed, Physiotherapists are clinicians and they use the 'clinical eye ball test'; as such, they may have pre-judged those in the high frequency group as having greater rehabilitation potential and in turn, given them higher priority. Rehabilitation potential is an elusive concept judged at the level of individual patients (rather than population-based predictive models of rehabilitation outcome), and draws on different sources of often experiential knowledge (16).

Despite the important limitations of our study, our findings are in keeping with other studies investigating the association between physiotherapy frequency and LOS (7), and with previous evidence that early physical rehabilitation care for acutely hospitalized older adults leads to functional benefits and can be safely executed $(17,18)$. Our results also reflect the known positive impact that exercise training seems to have on community-dwelling frail older adults (19).

Frail older patients admitted to hospital may benefit from as much physiotherapy as possible, and in that regard it would be important to maximize the feasibility of physical therapy in acute care. On occasions, frail patients have poor tolerance of exercise and mobilization due to severe acute illness, but on other occasions patients may not be available for physiotherapy sessions because they also need to undergo medical examinations or investigations, other 
multidisciplinary assessments or treatments, or simply have their protected time for having meals and spending time with their loved ones. It has been suggested that some of these challenges could be addressed by the implementation of personnel and patient schedules, in an attempt to maximize the number of selected patients, balance the workload of the physiotherapists, and minimize patient waiting times in their treatment day (20). Prospective studies are needed to examine the effect of physiotherapy frequency and intensity in hospital geriatric wards. 


\section{Acknowledgements}

We wish to thank all the members of the DME teams in our hospital, without which this initiative would have not been possible. Licensed access to the Trust's information systems is also gratefully acknowledged.

\section{Funding}

Permission to use the CFS was obtained from the principal investigator at Geriatric Medicine Research, Dalhousie University, Halifax, Canada. Funding was not required for this study.

\section{Conflict of Interest}

None. 


\section{References}

1. Clegg A, Young J, Iliffe S, Rikkert MO, Rockwood K. Frailty in elderly people. Lancet. 2013;381(9868):752-62.

2. Basic D, Shanley C. Frailty in an older inpatient population: using the clinical frailty scale to predict patient outcomes. Journal of aging and health. 2015;27(4):670-85.

3. Wallis SJ, Wall J, Biram RW, Romero-Ortuno R. Association of the clinical frailty scale with hospital outcomes. QJM : monthly journal of the Association of Physicians. 2015;108(12):943-9.

4. Hoogerduijn JG, Buurman BM, Korevaar JC, Grobbee DE, de Rooij SE, Schuurmans MJ. The prediction of functional decline in older hospitalised patients. Age and ageing. 2012;41(3):381-7.

5. Smith P, McKeon A, Blunt I, Edwards N. NHS hospitals under pressure: trends in acute activity up to 2022. Nuffield Trust Briefing, October 2014 Available online: http://wwwnuffieldtrustorguk/sites/files/nuffield/publication/financial_times_webpdf.

6. Soong J, Poots AJ, Scott S, Donald K, Woodcock T, Lovett D, et al. Quantifying the prevalence of frailty in English hospitals. BMJ open. 2015;5(10):e008456.

7. Peiris CL, Taylor NF, Shields N. Extra physical therapy reduces patient length of stay and improves functional outcomes and quality of life in people with acute or subacute conditions: a systematic review. Archives of physical medicine and rehabilitation. 2011;92(9):1490-500.

8. HJ B, S H, RW B, M-S K, S H. Gait speed is limited but improves over the course of acute care physical therapy. J Geriatr Phys Ther. 2012;35(3):140-4.

9. Landi F, Zuccalà G, Bernabei R, Cocchi A, Manigrasso L, Tafani A, et al. PHYSIOTHERAPY AND OCCUPATIONAL THERAPY: A Geriatric Experience in the 
Acute Care Hospital1. American Journal of Physical Medicine \& Rehabilitation. 1997;76(1):38-42.

10. Joosten E, Demuynck M, Detroyer E, Milisen K. Prevalence of frailty and its ability to predict in hospital delirium, falls, and 6-month mortality in hospitalized older patients. BMC geriatrics. 2014;14:1.

11. Rockwood K, Song X, MacKnight C, Bergman H, Hogan DB, McDowell I, et al. A global clinical measure of fitness and frailty in elderly people. CMAJ : Canadian Medical Association journal = journal de l'Association medicale canadienne. 2005;173(5):489-95.

12. Charlson ME, Pompei P, Ales KL, MacKenzie CR. A new method of classifying prognostic comorbidity in longitudinal studies: development and validation. Journal of chronic diseases. 1987;40(5):373-83.

13. Subbe CP, Kruger M, Rutherford P, Gemmel L. Validation of a modified Early Warning Score in medical admissions. QJM : monthly journal of the Association of Physicians. 2001;94(10):521-6.

14. van Swieten JC, Koudstaal PJ, Visser MC, Schouten HJ, van Gijn J. Interobserver agreement for the assessment of handicap in stroke patients. Stroke; a journal of cerebral circulation. 1988;19(5):604-7.

15. Quinn TJ, Dawson J, Walters MR, Lees KR. Reliability of the modified Rankin Scale: a systematic review. Stroke; a journal of cerebral circulation. 2009;40(10):3393-5.

16. Burton CR, Horne M, Woodward-Nutt K, Bowen A, Tyrrell P. What is rehabilitation potential? Development of a theoretical model through the accounts of healthcare professionals working in stroke rehabilitation services. Disability and rehabilitation. 2015;37(21):1955-60. 
17. Kosse NM, Dutmer AL, Dasenbrock L, Bauer JM, Lamoth CJ. Effectiveness and feasibility of early physical rehabilitation programs for geriatric hospitalized patients: a systematic review. BMC geriatrics. 2013;13(1):1-16.

18. Nolan J, Thomas S. Targeted individual exercise programmes for older medical patients are feasible, and may change hospital and patient outcomes: a service improvement project. BMC Health Services Research. 2008;8(1):1-8.

19. Theou O, Stathokostas L, Roland KP, Jakobi JM, Patterson C, Vandervoort AA, et al. The effectiveness of exercise interventions for the management of frailty: a systematic review. Journal of aging research. 2011;2011:569194.

20. Ogulata SN, Koyuncu M, Karakas E. Personnel and Patient Scheduling in the High Demanded Hospital Services: A Case Study in the Physiotherapy Service. Journal of Medical Systems. 2008;32(3):221-8. 
Table 1. Patients' characteristics and outcomes.

\begin{tabular}{|c|c|c|c|}
\hline & $\begin{array}{l}\text { Low frequency } \\
\text { physiotherapy } \\
\text { n=131 }\end{array}$ & $\begin{array}{l}\text { High frequency } \\
\text { physiotherapy } \\
\text { n=227 }\end{array}$ & $\begin{array}{c}\text { P for } \\
\text { difference }\end{array}$ \\
\hline Mean age, years (SD) & $84.6(5.4)$ & $85.0(5.3)$ & $0.392 *$ \\
\hline Female, \% & 64.1 & 60.8 & $0.532 \dagger$ \\
\hline Mean CFS score (SD) & $5.2(1.7)$ & $5.1(1.5)$ & $0.355^{*}$ \\
\hline CCI score (SD) & $3.3(3.0)$ & $3.0(2.8)$ & $0.335^{*}$ \\
\hline History of dementia, \% & 20.6 & 13.2 & $0.065 \dagger$ \\
\hline ED-MEWS score (SD) & $2.8(1.5)$ & $2.8(1.6)$ & $0.768^{*}$ \\
\hline Mean pre-admission mRS (SD) & $2.5(1.2)$ & $2.4(1.0)$ & $0.443^{*}$ \\
\hline Mean admission mRS (SD) & $3.4(1.3)$ & $3.7(1.3)$ & 0.010* \\
\hline Mean discharge mRS (SD) & $2.6(1.1)$ & $2.6(1.0)$ & $0.494^{*}$ \\
\hline $\begin{array}{l}\text { Mean change in mRS from } \\
\text { admission to discharge (SD) }\end{array}$ & $-0.7(0.9)$ & $-1.1(1.1)$ & $<0.001 *$ \\
\hline LOS, days (SD) & $13.4(11.5)$ & $7.3(7.8)$ & $<0.001 *$ \\
\hline $\begin{array}{l}\text { No formal package of care on } \\
\text { discharge (\%) }\end{array}$ & 41.2 & 50.7 & $0.085 \dagger$ \\
\hline Readmission at 30 days (\%) & 17.6 & 18.9 & $0.745 \dagger$ \\
\hline
\end{tabular}

*Independent samples Mann-Whitney U test; †Chi-squared test; SD: standard deviation; CFS: Clinical Frailty Scale; CCI: Charlson Comorbidity Index; ED-MEWS: Emergency Department Modified Early Warning Score; mRS: modified Rankin Scale; LOS: length of stay. 
Table 2. Multivariate regression analyses investigating predictors of change in modified Rankin Scale (discharge minus admission), length of stay and existence of formal care package on discharge.

\begin{tabular}{|c|c|c|c|c|c|c|}
\hline \multicolumn{7}{|c|}{ Dependent variable: change in mRS (discharge minus admission) } \\
\hline & \multicolumn{2}{|c|}{ Unstandardized Coefficients } & \multirow{2}{*}{$\begin{array}{c}\begin{array}{c}\text { Standardized } \\
\text { Coefficients }\end{array} \\
\text { Beta }\end{array}$} & \multicolumn{2}{|c|}{ 95\% Confidence Interval for B } & \multirow{2}{*}{$\mathrm{P}$} \\
\hline & B & Std. Error & & Lower Bound & Upper Bound & \\
\hline Age & 0.01 & 0.01 & 0.02 & -0.02 & 0.03 & 0.715 \\
\hline Gender & -0.12 & 0.13 & -0.05 & -0.39 & 0.14 & 0.365 \\
\hline CFS & 0.13 & 0.05 & 0.19 & 0.04 & 0.23 & 0.005 \\
\hline CCI & 0.00 & 0.02 & 0.01 & -0.04 & 0.05 & 0.880 \\
\hline $\begin{array}{l}\text { Known } \\
\text { dementia }\end{array}$ & -0.13 & 0.18 & -0.05 & -0.50 & 0.23 & 0.473 \\
\hline ED-MEWS & -0.04 & 0.04 & -0.06 & -0.12 & 0.04 & 0.341 \\
\hline $\begin{array}{l}\text { High frequency } \\
\text { physiotherapy }\end{array}$ & -0.40 & 0.13 & -0.18 & -0.66 & -0.13 & 0.003 \\
\hline \multicolumn{7}{|c|}{ Dependent variable: LOS, days } \\
\hline Age & -0.19 & 0.11 & -0.10 & -0.41 & 0.03 & 0.096 \\
\hline Gender & 1.66 & 1.21 & 0.08 & -0.72 & 4.03 & 0.171 \\
\hline CFS & 1.19 & 0.42 & 0.18 & 0.36 & 2.02 & 0.005 \\
\hline CCI & 0.32 & 0.21 & 0.09 & -0.10 & 0.74 & 0.138 \\
\hline $\begin{array}{l}\text { Known } \\
\text { dementia }\end{array}$ & -0.38 & 1.66 & -0.01 & -3.66 & 2.89 & 0.818 \\
\hline ED-MEWS & 0.38 & 0.37 & 0.06 & -0.35 & 1.11 & 0.310 \\
\hline $\begin{array}{l}\text { High frequency } \\
\text { physiotherapy }\end{array}$ & -5.83 & 1.20 & -0.27 & -8.19 & -3.47 & $<0.001$ \\
\hline \multicolumn{7}{|c|}{ Dependent variable: no formal care package on discharge } \\
\hline & & & Odds ratio & \multicolumn{2}{|c|}{$\begin{array}{l}\text { 95\% Confidence Interval for } \\
\text { Odds ratio } \\
\end{array}$} & \\
\hline Age & -0.13 & 0.03 & 0.88 & 0.83 & 0.93 & $<0.001$ \\
\hline Gender & -0.57 & 0.31 & 0.57 & 0.31 & 1.03 & 0.064 \\
\hline CFS & -0.69 & 0.12 & 0.50 & 0.40 & 0.63 & $<0.001$ \\
\hline CCI & -0.01 & 0.05 & 0.99 & 0.90 & 1.09 & 0.842 \\
\hline $\begin{array}{l}\text { Known } \\
\text { dementia }\end{array}$ & -0.07 & 0.43 & 0.94 & 0.40 & 2.18 & 0.878 \\
\hline ED-MEWS & -0.10 & 0.09 & 0.91 & 0.76 & 1.09 & 0.296 \\
\hline $\begin{array}{l}\text { High frequency } \\
\text { physiotherapy }\end{array}$ & 0.76 & 0.31 & 2.13 & 1.16 & 3.92 & 0.015 \\
\hline
\end{tabular}

CFS: Clinical Frailty Scale; CCI: Charlson Comorbidity Index; ED-MEWS: Emergency Department Modified Early Warning Score; mRS: modified Rankin Scale; LOS: length of stay. 